University of Wollongong

Research Online

Faculty of Engineering - Papers (Archive)

Faculty of Engineering and Information

Sciences

2008

\title{
A Galvanic cell driven controlled release system based on conducting polymers
}

Caiyun Wang

University of Wollongong, caiyun@uow.edu.au

Chee 0. Too

University of Wollongong, chee@uow.edu.au

Philip G. Whitten

University of Wollongong, whitten@uow.edu.au

G G. Wallace

University of Wollongong, gwallace@uow.edu.au

Follow this and additional works at: https://ro.uow.edu.au/engpapers

Part of the Engineering Commons

https://ro.uow.edu.au/engpapers/3259

\section{Recommended Citation}

Wang, Caiyun; Too, Chee O.; Whitten, Philip G.; and Wallace, G G.: A Galvanic cell driven controlled release system based on conducting polymers $2008,605-611$.

https://ro.uow.edu.au/engpapers/3259

Research Online is the open access institutional repository for the University of Wollongong. For further information contact the UOW Library: research-pubs@uow.edu.au 


\title{
A galvanic cell driven controlled release system based on conducting polymers
}

\author{
Caiyun Wang, Philip G. Whitten, Chee O. Too and Gordon G. Wallace*
}

ARC Centre of Excellence for Electromaterials Science Intelligent Polymer Research Institute, University of Wollongong Northfields Avenue, Wollongong, NSW 2522, Australia.

* Corresponding author.

Tel: +61 2 4221 3127; fax: +61242213114

Email: gwallace@uow.edu.au 


\section{Abstract}

A self-powered controlled release system is achieved via galvanic coupling of a conducting polymer and a zinc anode. Release of an anionic dye molecule, phenol red $(\mathrm{PR})$, as the polymer is reduced is quantified. Triggered release using the galvanic cell is demonstrated in a freeze-thaw experiment when melting of the electrolyte completes the galvanic cell and enables oxidation/reduction to occur.

Keywords: Controlled release, phenol red, conducting polymer, electrochemical quartz crystal microbalance, galvanic cell. 


\section{Introduction}

Polymer structures capable of triggering release in response to discrete thermal transitions ${ }^{[1,2]}, \mathrm{pH}^{[3,4]}$ or electrical stimuli ${ }^{[5-7]}$ have been demonstrated previously. Those based on the use of electrical stimulation have the advantage that the release profile can be tuned by the nature of the stimulation conditions (the current/potential magnitude and frequency) employed. They have the disadvantage of requiring a power supply of some description for operation.

Conducting polymers represent a class of materials capable of responding to electrical stimulation to induce controlled release. This ability can be traced to the inherent redox capabilities of these polymer structures according to:
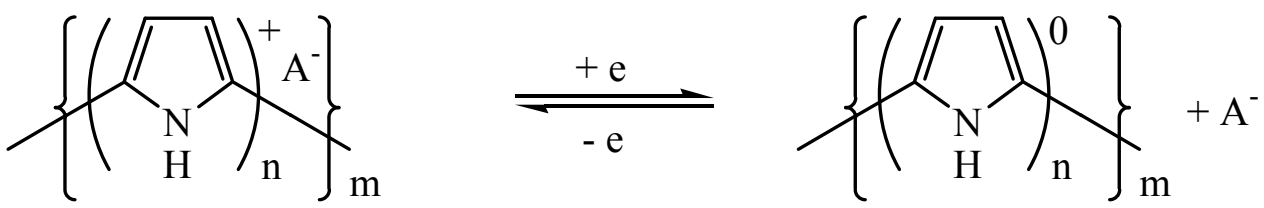

and/or
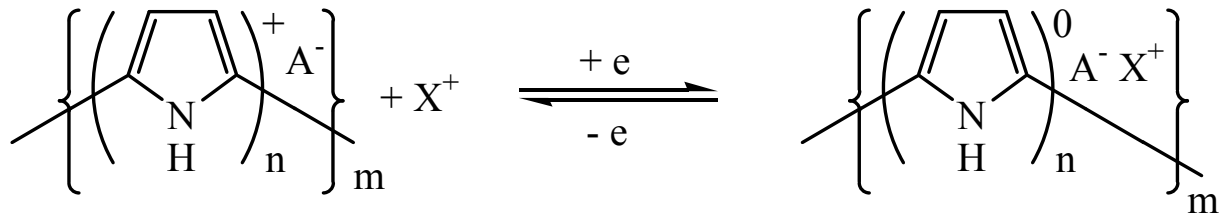

Anions $\left(\mathrm{A}^{-}\right.$- Equation 1) are expelled into the solution during the reduction process ${ }^{[8,9]}$. However, when immobile counter-anions are employed in the conjugated conducting 
polymers, the redox mechanism involves the entry of cations $\left(\mathrm{X}^{+}-\right.$Equation 2$)$ during reduction and expulsion during oxidation ${ }^{[10,11]}$. Obviously these processes can be used to provide release on demand systems for either cations or anions ${ }^{[12,13]}$.

For example, it has been reported that anthraquinone disulphonic acid (AQSA) can be electrochemically released from a polypyrrole matrix ${ }^{[14]}$, with the rate of release determined by the potential applied. The electrically stimulated release of sulfosalicyclic acid (SSA) from polypyrrole has also been reported ${ }^{[15]}$. In other work, Pyo and Reynolds ${ }^{[16]}$ incorporated adenosine 5'-triphosphate (ATP) as the counter-anion into polypyrrole (PPy) and demonstrated electrochemical release of the molecule.

In this work, phenol red (Figure 1) sodium salt dye was chosen as the molecular dopant. Phenol red was incorporated as a counter-anion into the polypyrrole matrix during electrochemical growth. When this polymer was stimulated at negative potential, the dopant, phenol red, was expelled and migrated into the solution, and the solution exhibited a red colour which can be easily observed by eye. This, like most conducting polymer controlled release systems, required an external power supply to apply the required electrochemical stimulus. Therefore, a further novel development of this work was the adoption of a galvanic cell system whereby the dye was released when the PPyphenol red electrode was connected to a zinc counter electrode in an electrolyte. This system required no external power source to trigger and control the dye release. Here we describe a self-powered controlled release system, particularly for autonomous applications, based on coupling a conducting polymer cathode to a zinc anode. It is 
envisaged that such systems would find applications in situations where the couple is immediately connected. For example, a self powered controlled release system or where the cell is coupled by a change in environmental conditions (e.g. a thawing electrolyte) to act as a triggered monitoring system.

\section{Materials and methods}

\subsection{Polymer electrosynthesis and characterization}

Phenol Red (PR) dye was incorporated into polypyrrole as a dopant in this experiment. This polymer was electrosynthesised galvanostatically at a current density of $0.5 \mathrm{~mA} \mathrm{~cm}-$ ${ }^{2}$ on stainless steel mesh or gold coated quartz crystal from Milli-Q water containing 0.1 M pyrrole and $5 \mathrm{mM}$ phenol red sodium salt. Phenol red sodium salt (Aldrich) was used as-received and pyrrole (Merck) was freshly distilled. The solution was purged with nitrogen before use. The charge consumed during the electrosynthesis of polypyrrole was 1.0 $\mathrm{C} \mathrm{cm}^{-2}$. Stainless steel mesh was used as counter electrode, and the reference electrode was $\mathrm{Ag} / \mathrm{AgCl}(3 \mathrm{M} \mathrm{NaCl})$. After deposition the polymer coated electrode was rinsed thoroughly with deionised $\mathrm{H}_{2} \mathrm{O}$, then soaked in acetonitrile for 10 minutes to extract $\mathrm{H}_{2} \mathrm{O}$ from the polymer matrix. The as-polymerized polymer coated electrode was dried in air for 48 hours before use.

All the electrochemical properties were investigated using a standard one compartment three-electrode cell with a stainless steel mesh counter electrode, and $\mathrm{Ag} / \mathrm{AgCl}(3 \mathrm{M}$ $\mathrm{NaCl})$ reference electrode. Cyclic voltammetry (CV) was carried out using an EG\&G 
PAR 363 Potentiostat/Galvanostat, a MacLab 400, and EChem v 1.3.2 software (AD Instruments).

PPy-PR samples, as electrosynthesised and after dye release, were sent to the Microanalytical Unit of the Australian National University for elemental analysis.

\subsection{EQCM}

The resonance frequency of the polypyrrole coated quartz crystal was measured in-situ during both electrochemical synthesis of, and the electrochemical characterization of the polypyrrole with a Standford Research System (QCM 200) Quartz Crystal Microbalance. The gold quartz crystals were obtained from Standford Research Systems, and have an unloaded resonant frequency of approximately $5 \mathrm{MHz}$. The electrochemical surface area of the crystal $\left(1.37 \mathrm{~cm}^{2}\right)$ is much larger than the oscillation surface area $\left(0.4 \mathrm{~cm}^{2}\right)$ meaning that edge effects do not affect the frequency measurement. The crystal loaded with polypyrrole was rinsed with Milli-Q water and dried slowly in air to avoid any crack formation in the film.

Mass change was calculated directly from the change in resonant frequency using the Sauerbrey equation ${ }^{[18]}$. It gives the change $\Delta f$ in the oscillation frequency of a piezoelectric quartz crystal as a function of the mass $\Delta m$ added to the crystal:

$$
\Delta f=\frac{-2 \Delta m f_{0}^{2}}{A \sqrt{\rho_{q} \mu_{q}}}=-\frac{2 f_{0}^{2}}{A \rho_{q} v_{q}} \Delta m
$$


Here, $f_{0}$ is the resonant frequency of the crystal, $A$ is the active area of the crystal (between electrodes), $\rho_{q}$ is the density of quartz, $\mu_{q}$ is the shear modulus of quartz, and $v_{q}$ is the shear wave velocity in quartz. To a first approximation the mass change per $\mathrm{cm}^{2}$ can be calculated by:

$$
\mathrm{m}[\mathrm{ng}]=\text { relative frequency } / 0.0566
$$

The polypyrrole coated quartz crystal was immersed in the testing electrolyte $(0.1 \mathrm{M}$ sodium dodecyl sulfate (SDS)) for 30 minutes before electrochemical characterization of the film was initiated. This procedure allowed the electrolyte to swell the polypyrrole, and hence minimize the mass change during electrochemical cycling due to the swelling of the previously dried polypyrrole film.

\subsection{UV-vis spectrum}

The release of dye into the solution from the polymer film was monitored and characterised using UV-vis spectroscopy. Vigorous stirring was applied continuously during the dye releasing process to maintain the homogeneity of the solution. The UV-vis spectra of the solution containing phenol red dye in $0.1 \mathrm{M} \mathrm{NaCl}$ or $0.1 \mathrm{M}$ SDS were recorded between $300 \mathrm{~nm}$ and $1100 \mathrm{~nm}$ using a Shimadzu UV 1601 spectrophotometer.

\subsection{Controlled dye release}

Initially, dye release at controlled potentials $(-300,-500$ and $-800 \mathrm{mV}$ vs $\mathrm{Ag} / \mathrm{AgCl}(3 \mathrm{M}$ $\mathrm{NaCl}$ )) was investigated in $0.1 \mathrm{M} \mathrm{SDS}$ electrolyte. Following this, a Galvanic cell system 
comprising the PPy-PR on stainless steel mesh as working electrode $\left(1.2 \mathrm{~cm}^{2}\right)$, a $\mathrm{Zn}$ electrode $\left(6 \mathrm{~cm}^{2}\right)$ as counter electrode, and 0.1 M SDS electrolyte was considered for dye release without the need for an external power source.

This type of galvanic ell was put into the freezer $\left(-35^{\circ} \mathrm{C}, \mathrm{MF} 285\right.$, Dometic medical systems, Australia) overnight to completely freeze the electrolyte. The electrolyte was gradually thawed out in an ambient environment when the frozen cell was taken out of the freezer. A novel application of the Galvanic cell system was then investigated where the dye release was triggered by the thawing of the electrolyte. In this experiment the temperature and current variations vs time elapsed were recorded.

\section{Results and Discussion}

\subsection{Electrodeposition of PPy-PR}

The oxidation of pyrrole to form a polypyrrole film containing the dye molecule as the molecular dopant can be depicted according to Equation (5) ${ }^{[17]}$ :

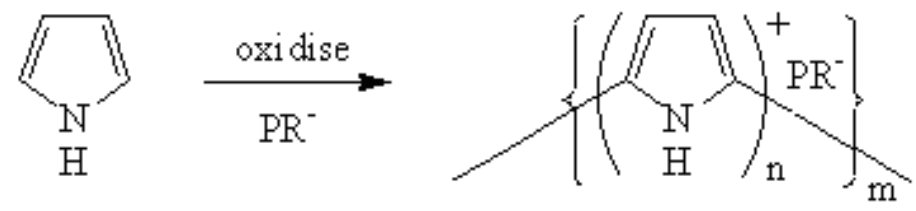


Using EQCM, the potential and relative frequency or mass variation on the gold coated crystal were recorded during the polymer growth process (Figure 2). The chronopotentiogram (Figure 2a) exhibits an initial spike due to charging of the double layer, followed by a slowly decreasing potential as polymer growth proceeded. The decreasing potential is indicative of conducting polymer deposition on the electrode. The chronopotentiogram obtained during polymer growth on the stainless steel mesh substrate was similar (not shown).

The mass of polymer deposited on the gold coated crystal working electrode increased with time during the growth process, in a linear fashion (Figure $2 \mathrm{~b}$ ).

\subsection{Cyclic voltammetry and mass variation}

Cyclic voltammetry of PPy-PR on a gold coated crystal in an EQCM cell was performed at a scan rate of $10 \mathrm{mV} \mathrm{s}^{-1}$ over the potential range $-0.80 \mathrm{~V}$ to $0.80 \mathrm{~V}$ (versus $\mathrm{Ag} / \mathrm{AgCl}$ reference electrode) in an electrolyte consisting of $0.1 \mathrm{M}$ SDS in aqueous media (Figure 3). The changes in mass were recorded simultaneously. A redox couple (A/B) was observed in the potential region of -800 to $400 \mathrm{mV}$. The reduction process is associated with concomitant expulsion of anions or the insertion of cations as shown in Equations (1) and (2) respectively and vice versa for the oxidation reaction.

It can be seen from Figure 3(b) that the mass change was dominated by cation $\left(\mathrm{Na}^{+}\right)$ motion in the electrolyte of SDS. There was a decrease in mass during the anodic scan, 
and an increase in mass during the cathodic scan. Such a pattern confirms that cation movement (Equation 2) is the dominant reaction, which is not surprising given the relatively large size of the phenol red dopant anion. However, the fact that phenol red expulsion was visually observed during the cathodic scan also infers that it was expelled during the earlier part of the cathodic scan before $\mathrm{Na}^{+}$incorporation became dominant resulting in a mass increase of the polymer.

\subsection{UV-visible spectroscopy}

The UV-vis spectrum of phenol red sodium salt in $0.1 \mathrm{M}$ SDS or $0.1 \mathrm{M} \mathrm{NaCl}$ is shown in Figure 4 (a). Two bands are observed for the dye in 0.1 M SDS where the primary band occurred at $559 \mathrm{~nm}$. The bands at $361 \mathrm{~nm}$ and $559 \mathrm{~nm}$ could be assigned respectively to $\pi-\pi^{*}$ and excitonic transitions. The UV-visible spectrum obtained for the solution used for controlled release was identical to that obtained for the phenol red sodium salt.

Using standard solutions absorbance intensities of the primary band were examined at a series of concentration of dye in 0.1 M SDS, and they were plotted against the dye concentration as shown in the inset Figure 4 (b). The absorbance intensity was monitored during the controlled release experiments and used to calculate the amount of dye released into the solution. Polymer PPy-PR was soaked in 0.1 M SDS for 24 hours to investigate if dye could be self-released into the solution, and no peak was shown in UVvis spectrum, which indicates that $\mathrm{PR}^{-}$could not migrate out of the polymer matrix and release into the solution without the electrical power or the amount of this anion was too 
trivial to be detected. The absorbance intensities of dye obtained in this work can be attributed to the release stimulated.

\subsection{Dye release by controlled potential}

The dye release process from the polymer film PPy-PR was investigated at controlled potentials of $-300,-500$ and $-800 \mathrm{mV}$, respectively using samples that were identically prepared. The amount of anion $\mathrm{PR}^{-}$released in the process was calculated from the absorbance intensity shown at the primary band maximum $(559 \mathrm{~nm})$ and using the linear regression equation as shown in Figure 4 (b). The percentage and the concentration of dye released (calculated using the amount originally incorporated) were plotted vs time (Figure 5). It can be seen that the onset time for dye release and the subsequent rate of release was dependent on the potential applied. The effect on the onset time for release is obvious if we consider the time required to effect $10 \%$ release as summarized in Table 1 . It took $205,20.8$ and 1.6 minutes at $-300,-500$ and $-800 \mathrm{mV}$, respectively. Interestingly, for applied potentials of $-0.30 \mathrm{~V}$ and $-0.50 \mathrm{~V}$, the release appears to occur in three stages. From EQCM data this would be attributed to the initial reduction process being dominated by cation insertion, then anion release. At -500 and $-800 \mathrm{mV}$, the amount of dye anion released significantly increased initially before reaching a plateau. At $-300 \mathrm{mV}$, however, an obvious activation process was exhibited followed by the same dye release trend. The initial rate of release was calculated based on the first stage and listed in table 1. The results show that the initial release rate was much higher at $-800 \mathrm{mV}$ than that at $500 \mathrm{mV}$ and $-300 \mathrm{mV}$. At $-800 \mathrm{mV}, 63 \%$ of anion $\mathrm{PR}^{-}$was expelled into the solution 
from the polymer in $70 \mathrm{mins}$; the charge consumed was $4468 \mathrm{mC}$. At $-500 \mathrm{mV}$, only $33 \%$ of $\mathrm{PR}^{-}$was expelled in 160 mins; the charge consumed was $2998 \mathrm{mC}$. At -300 mV, RED expulsion was $41 \%$ in 387 mins and the charge consumed was $3210 \mathrm{mC}$.

Elemental analyses of PPy-PR', as electrosynthesised and after dye release at - $800 \mathrm{mV}$ vs $\mathrm{Ag} / \mathrm{AgCl}(3 \mathrm{M} \mathrm{NaCl})$, indicated that $58 \%$ of anion $\mathrm{PR}^{-}$was expelled which is in good agreement with the efficiency calculated here. The monomer to counter-anion ratio was also calculated from the elemental analyses and showed that the as electrosynthesised PPy-PR ${ }^{-}$had a ratio of $3 \mathrm{Py}: 1 \mathrm{PR}^{-}$whereas after dye release the ratio became $7 \mathrm{Py}: 1$ $\mathrm{PR}^{-}$

To further investigate the ion exchange process during this discharging process, EQCM measurements were also performed at the controlled potential of $-800 \mathrm{mV}$ to detect the mass variation with time (Figure 6). It can be seen clearly that the mass shows an initial transient increase then decrease in $0.1 \mathrm{M}$ SDS. The mass increase can be explained by $\mathrm{Na}^{+}$insertion into the polymer and the mass loss is due to the anion $\mathrm{PR}^{-}$migrating from the polymer matrix. It appears that cation insertion dominates during reduction at the first discharge stage, but after a defined period anion expulsion is more evident.

\subsection{Dye release in a galvanic cell system}

The dye release process was also investigated in a galvanic cell system comprised of a PPy-PR working electrode and a Zn counter electrode in 0.1 M SDS in Milli-Q water. 
This galvanic cell produced an initial voltage of $1.20 \mathrm{~V}$ before the release procedure was started. In this cell, the $\mathrm{Zn}$ was oxidized and migrated into the solution as $\mathrm{Zn}^{2+}$ whereas the PPy-PR was reduced resulting in the release of $\mathrm{PR}^{-}$into the solution. In this way, dye release can be achieved without the need of an external power source. The dye release efficiency calculated from the absorbance intensity at the primary band maximum of 559 $\mathrm{nm}$ together with its concentration was plotted against time (Figure 7). A very similar dye release trend was observed in the galvanic cell compared with that at the controlled potential of $-800 \mathrm{mV}$. The dye release rate was rapid at the first stage, and $55 \%$ of anion $\mathrm{PR}^{-}$was expelled from the polymer matrix in only $740 \mathrm{~s}$. The proportion of $\mathrm{PR}^{-}$that migrated into the solution compared with the initial amount was $67 \%$ in 60 mins; which is similar to $62.7 \%$ in 70 mins achieved by the controlled potential method at $-800 \mathrm{mV}$.

The variation of the potential of the working electrode PPy-PR during this dye release process was recorded against an $\mathrm{Ag} / \mathrm{AgCl}$ reference electrode, and is shown in Figure 8 (curve a). The amount of charge consumed during this process accumulated with time and is also shown in Figure 8 (curve b). It can be seen clearly that the potential dropped sharply when the polymer was reduced, then an obvious plateau appeared followed by potential decrease again, which implies that different reaction processes were involved. The appearance of the plateau at $-0.77 \mathrm{~V}$ indicates that the structure of the polymer was not affected or did not change much during this reduction process. It can be ascribed to the insertion of small $\mathrm{Na}^{+}$. The polymer structure was changed when the large anions were expelled from the polymer matrix, causing the potential to drop again. The results 
show two types of redox reactions, cation insertion and anion expulsion occurred during discharge as well observed with the controlled potential experiments.

\subsection{A novel temperature triggered galvanic cell device}

This dye release process in a galvanic cell was also investigated with a frozen electrolyte that was allowed to thaw at room temperature (Figure 9). When the electrolyte was frozen, as expected, no current flowed in the system. However, as the temperature rose and the electrolyte thawed, the redox reaction was initiated and a current was produced concomitant with the release of $\mathrm{PR}^{-}$dye. The colour change in the electrolyte is obvious from the photographs included in Figure 9. The current reached a maximum after $6000 \mathrm{~s}$ before decreasing as the PPy-PR was expended in the galvanic cell.

\section{Conclusions}

The controlled release of phenol red ( $\left.\mathrm{PR}^{-}\right)$dye from a polypyrrole-phenol red (PPy-PR) conducting polymer was achieved. The rate and efficiency of release increased as the controlled potential was made more cathodic. CV experiments with PPy-PR on a gold coated quartz crystal in an EQCM cell showed that the redox reactions of this polymer in 0.1 M SDS was predominantly associated with cation $\left(\mathrm{Na}^{+}\right)$movement. However, controlled potential experiments at $-0.80 \mathrm{~V}$ in an EQCM cell showed that on reduction of PPy-PR in $0.1 \mathrm{M}$ SDS, initially $\mathrm{Na}^{+}$incorporation predominated but $\mathrm{PR}^{-}$release became dominant at longer times. A further advance on this technology was also achieved by use 
of a galvanic cell system in which one electrode consisted of PPy-PR on stainless steel mesh and the other electrode was zinc metal. When the two electrodes were connected, a current flowed and $\mathrm{PR}^{-}$was released. This release could be controlled by the freezing and thawing of the electrolyte. 


\section{Acknowledgements}

We wish to thank the Australian Research Council and the CRC SmartPrint for their financial support. We also acknowledge invaluable technical discussions with Noel Clark and Nafty Vanderhoek (CSIRO) as well as Bjorn Winther-Jensen (Monash University). 


\section{References}

[1] E. Kharlampieva, V. Kozlovskaya, J. Tyutina and S.A. Sukhishvili, HydrogenBonded Multilayers of Thermoresponsive Polymers, Macromolecules 38(25) (2005) 10523-10531.

[2] K.S. Oh, S.K. Han, Y.W. Choi, J.H. Lee, J.Y. Lee and S.H. Yuk, Hydrogenbonded polymer gel and its application as a temperature-sensitive drug delivery system, Biomaterials 25(12) (2004) 2393-2398.

[3] T. Serizawa, D. Matsukuma and M. Akashi, Loading and Release of Charged Dyes Using Ultrathin Hydrogels, Langmuir 21(17) (2005) 7739-7742.

[4] D.T. Auguste, S.P. Armes, K.R. Brzezinska, T.J. Deming, J. Kohn, R.K. Prud' homme, PH triggered release of protective poly(ethylene glycol)-bpolycation copolymers from liposomes, Biomaterials 27(12) (2006) 2599-2608.

[5] P.M. George, D.A. LaVan, J.A. Burdick, C.Y. Chen, E. Liang and R. Langer, Electrically controlled drug delivery from biotin-doped conductive polypyrrole, Adv. Mater. 18(5) (2006) 577-581.

[6] R. Wadhwa, C.F. Lagenaur and X.T. Cui, Electrochemically controlled release of dexamethasone from conducting polymer polypyrrole coated electrode, J. Controlled Release 110(3) (2006) 531-541.

[7] C.L. Recksiedler, B.A. Deore and M.S. Freund, A Novel Layer-by-Layer Approach for the Fabrication of Conducting Polymer /RNA Multilayer Films for Controlled Release, Langmuir 22(6) (2006) 2811-2815. 
[8] T. Yeu, K.-M Yin, J. Carbajal and R.-E White, Electrochemical characterization of electronically conductive polypyrrole on cyclic voltammograms, J. Electrochem. Soc. 138(10) (1993) 2869-77.

[9] A. Talaie and G.G. Wallace, The effect of the counterion on the electrochemical properties of conducting polymers - a study using resistometry, Synth. Met. 63(2) (1994) 83-88.

[10] C. Baker, Y.-J. Qiu and J.R. Reynolds, Electrochemcially induced charge and mass transport in polypyrrole/poly(styrenesulfonate) molecular composites, J. Phys. Chem. 95 (1991) 4446-4452.

[11] D.A. Chesher, P.A. Christensen and A. Hamnett, Anion movement and carrier type in polypyrrole/dodecyl sulfate, J. Chem. Soc. Faraday Trans. 89(2) (1993) 303309.

[12] B. Zinger and L.L. Miller, Timed release of chemicals from polypyrrole films, J. Am. Chem. Soc. 106(22) (1984) 6861-31.

[13] Q.X. Zhou and L.L. Miller, Electrochemically controlled binding and release of protonated dimethyldopamine and other cations from poly( $N$-methylpyrrole)/polyanion composite redox polymers, J. Electroanal Chem., 261 (1989) $147-164$

[14] Y. Lin and G.G. Wallace, Factors influencing electrochemical release of 2,6anthraquinone disulphonic acid from polypyrrole, J. Controlled Release 30 (1994) $137-142$ 
[15] B. Massoumi and A. Entezami, Controlled release of sulfosalicylic acid during electrochemical switching of conducting polymer bilayers, Eurp. Polymer, J. 37(5) (2001) 1015-1020.

[16] M. Pyo and J.R. Reynolds, Poly(pyrrole adenosine 5'-triphosphate) (PP-ATP) and conducting polymer bilayers for transport of biologically active ions, Synth. Met. 71(1-3) (1995) 2233-6.

[17] G.G. Wallace, G.M. Spinks, P.R. Teasdale, Conducting Electroactive Polymers: Intelligent Materials Systems, Technomic Publishing Company, Lancaster, USA, 1997.

[18] G. Sauerbrey, The use of quartz oscillators for weighing thin layers and for microweighing, Z. Phys. 155 (1959) 206-22. 


\section{Figure and table captions}

Fig. 1. Structure of phenol red sodium salt.

Fig. 2. Chronopotentiogram (a) and mass plot (b) for the deposition of polypyrrole, at a current density of $0.5 \mathrm{~mA} \mathrm{~cm}{ }^{-2}$, from an aqueous solution containing $0.1 \mathrm{M}$ pyrrole and $0.5 \mathrm{M}$ phenol red sodium salt.

Fig. 3. Cyclic voltammogram (a) and EQCM response (b) of PPy-phenol red on a quartz crystal cell in $0.1 \mathrm{M}$ SDS. Scan rate: $10 \mathrm{mV} \mathrm{s}^{-1}$.

Fig. 4. UV-vis absorbance spectrum of phenol red sodium salt dye (a), and correlation between ABS and concentration of dye in 0.1M SDS (b).

Fig. 5. Dye release efficiency (curve 1, 3 and 5) and concentration of dye released (curve 2, 4 and 6) in $0.1 \mathrm{M}$ SDS at controlled potentials of -800 (curve 1 and 2), -500 (curve 3 and 4) and $-300 \mathrm{mV}$ (curve 5 and 6) vs $\mathrm{Ag} / \mathrm{AgCl}(3 \mathrm{M} \mathrm{NaCl})$.

Fig. 6. Mass vs Time plot of PPy-phenol red when poised at $-0.80 \mathrm{~V}$ vs $\mathrm{Ag} / \mathrm{AgCl}(3 \mathrm{M}$ $\mathrm{NaCl}$ ) reference electrode.

Fig. 7. Dye release efficiency (1) and concentration of dye released (2) from polymer PPy-PR in 0.1 M SDS, in a Galvanic cell system.

Fig. 8. Potential variation of polymer PPy-PR (a) and charge consumed (b) during the dye release process in a Galvanic cell system.

Fig. 9. Current and temperature variation during the thawing process of the frozen electrolyte in a Galvanic cell. Photograph A: electrolyte frozen; B: electrolyte thawing (mixture of solid and liquid); C: electrolyte fully thawed showing the progress of dye release during this thawing process. 
Table 1 Initial release rate of dye at difference potentials in 0.1 M SDS

\begin{tabular}{ccc}
\hline Potential $(\mathrm{V})$ & $\begin{array}{c}\text { Time to reach 10\% release } \\
(\mathrm{min})\end{array}$ & $\begin{array}{c}\text { Initial rate of release }(\mathrm{mM} . \\
\left.\min ^{-1} \times 10^{-2}\right)\end{array}$ \\
\hline-0.30 & 205 & 0.0008 \\
-0.50 & 20.8 & 0.0112 \\
-0.80 & 1.6 & 0.2573 \\
\hline
\end{tabular}<smiles>O=C1C=CC(=C(c2ccc(O)cc2)c2ccccc2S(=O)(=O)[OH2+])C=C1</smiles>

Fig.1 


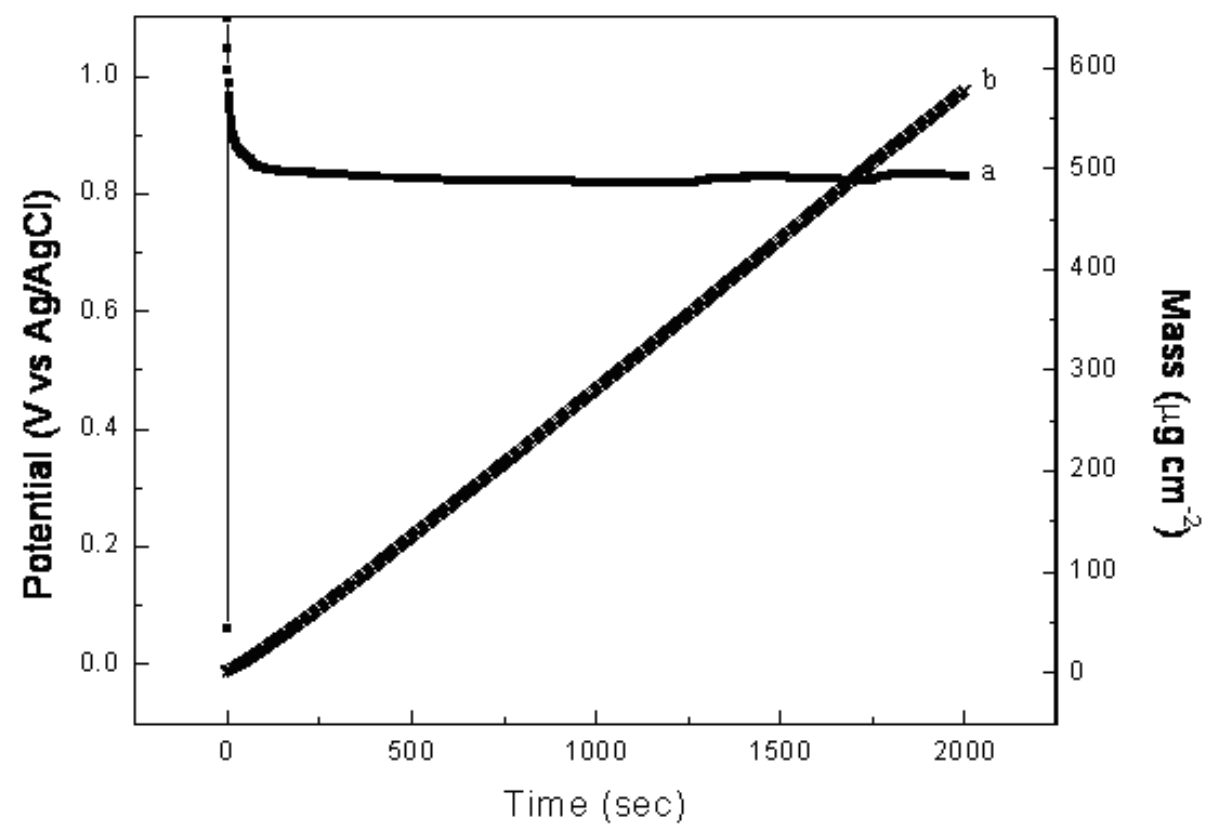

Fig.2

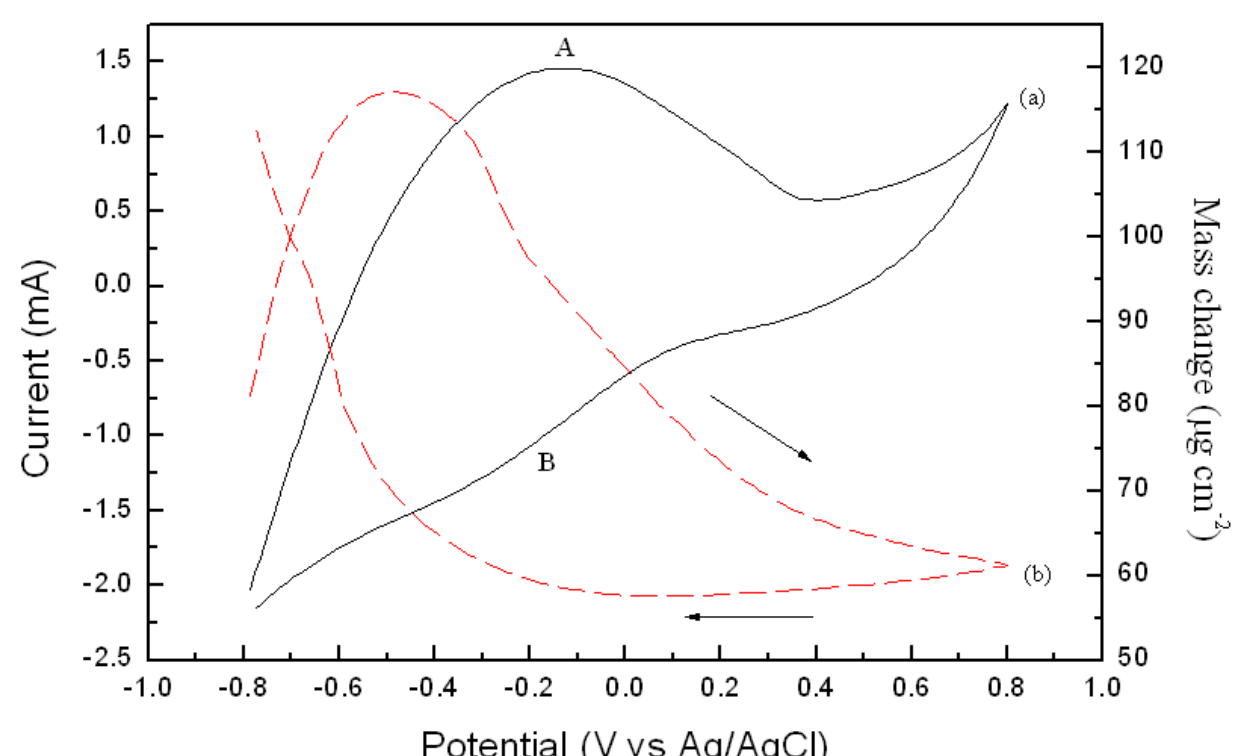

Fig. 3 


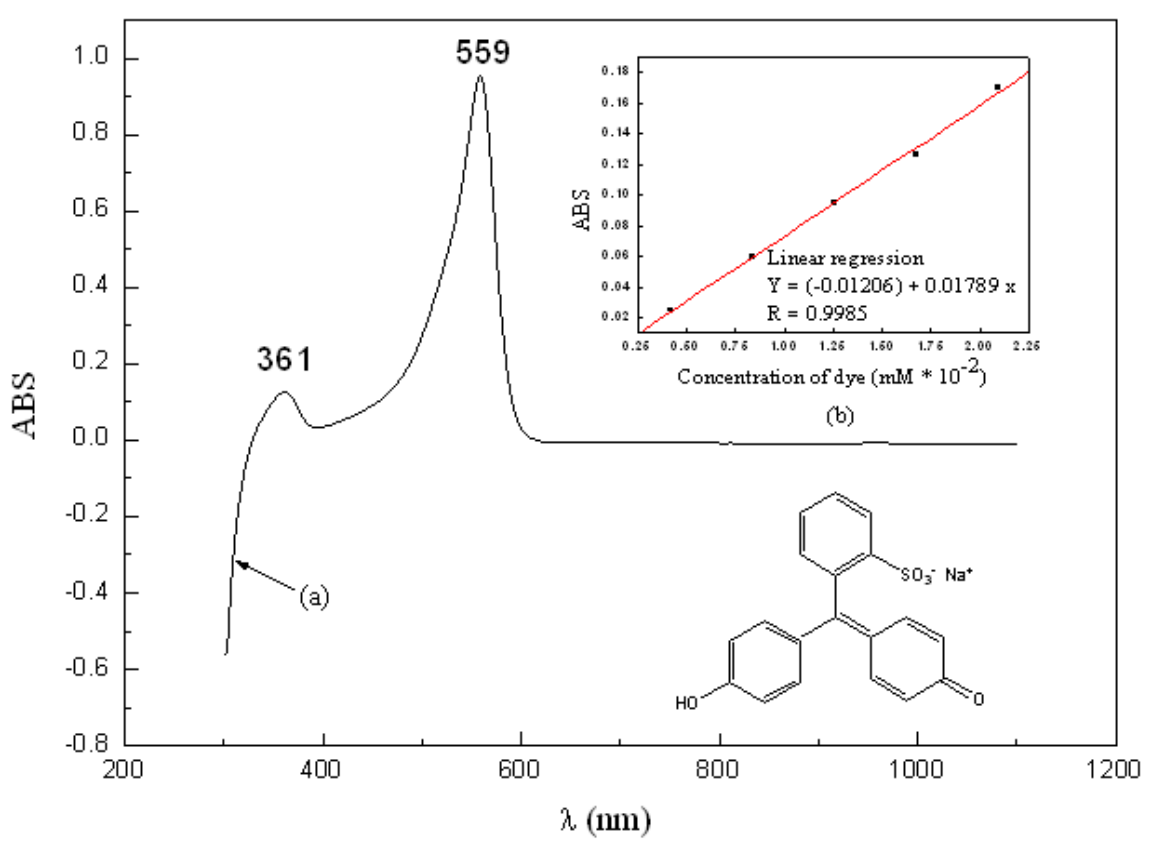

Fig. 4

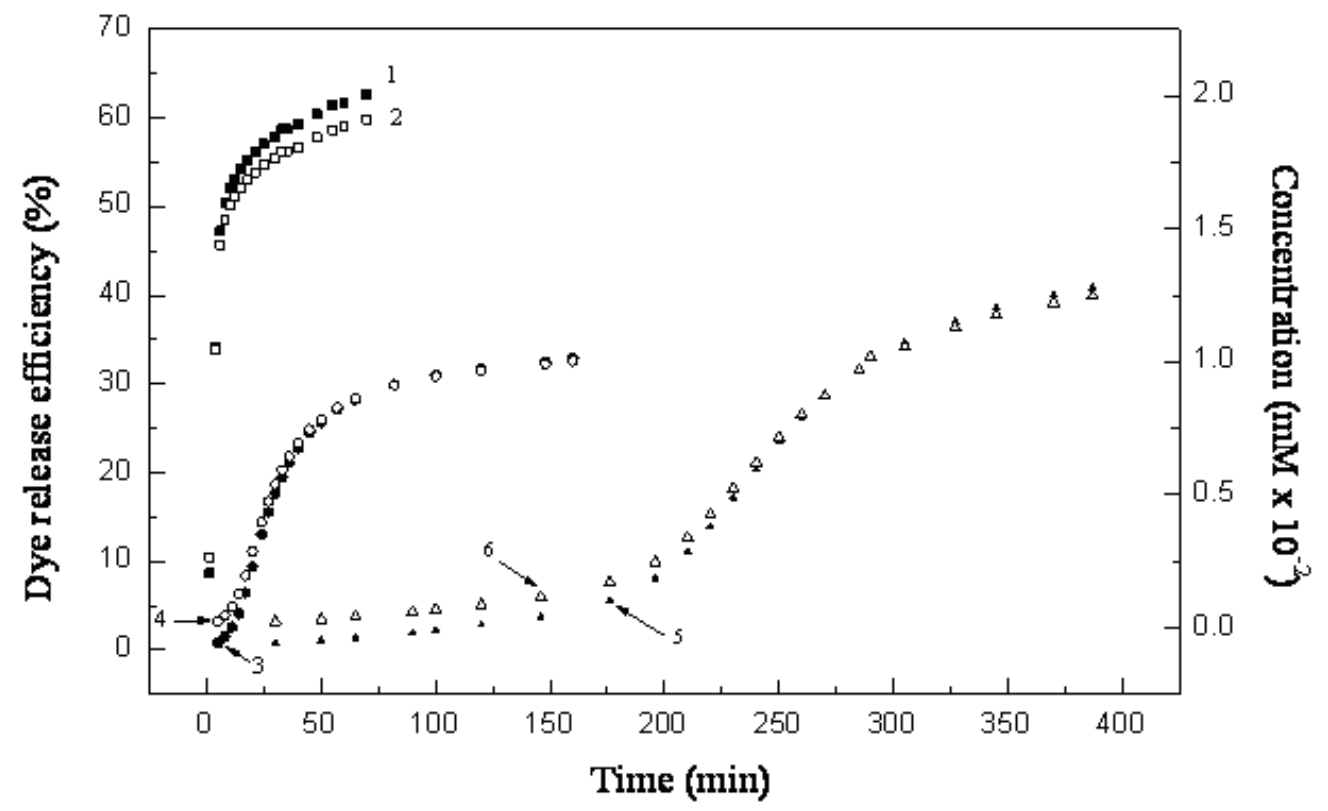

Fig.5 


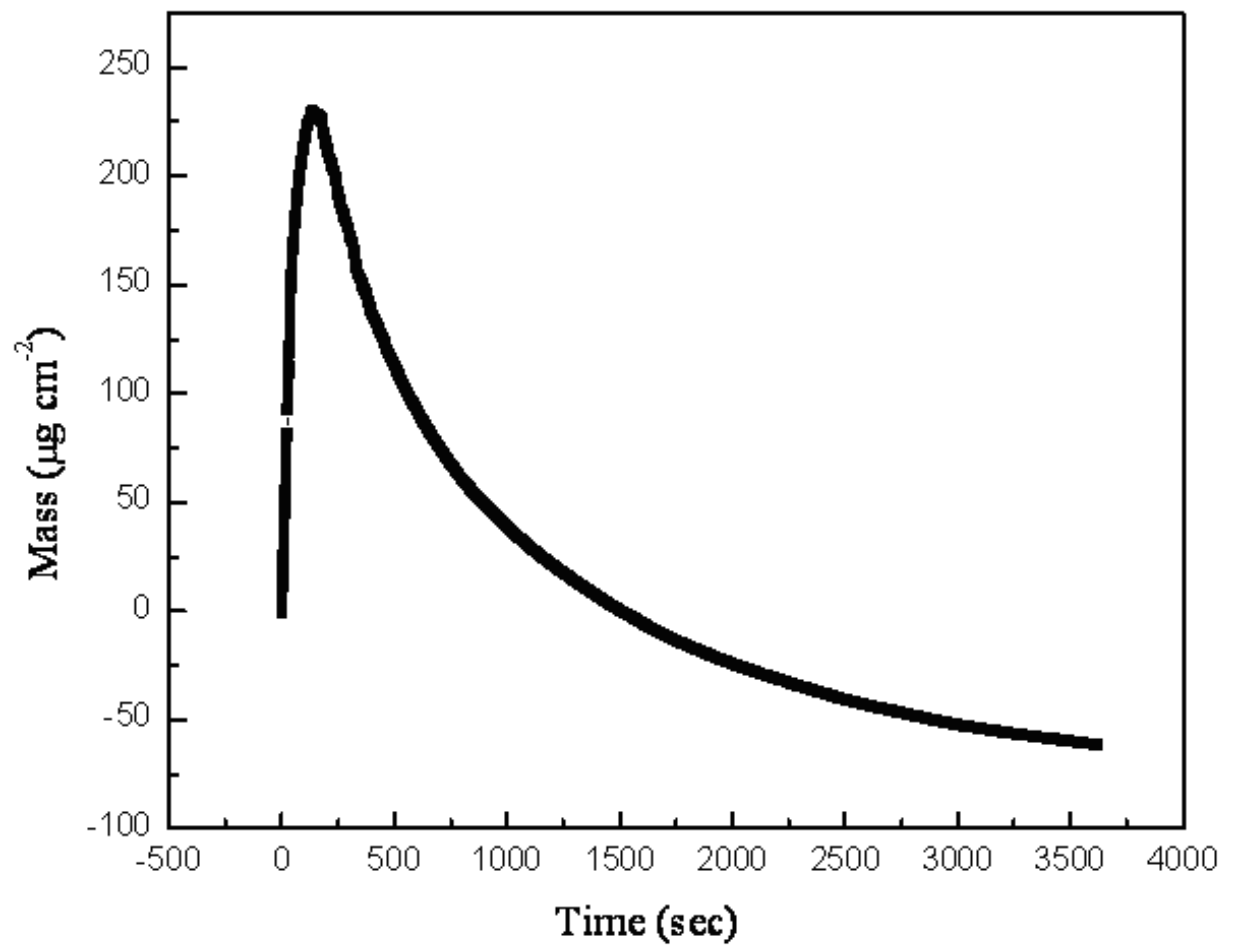

Fig.6

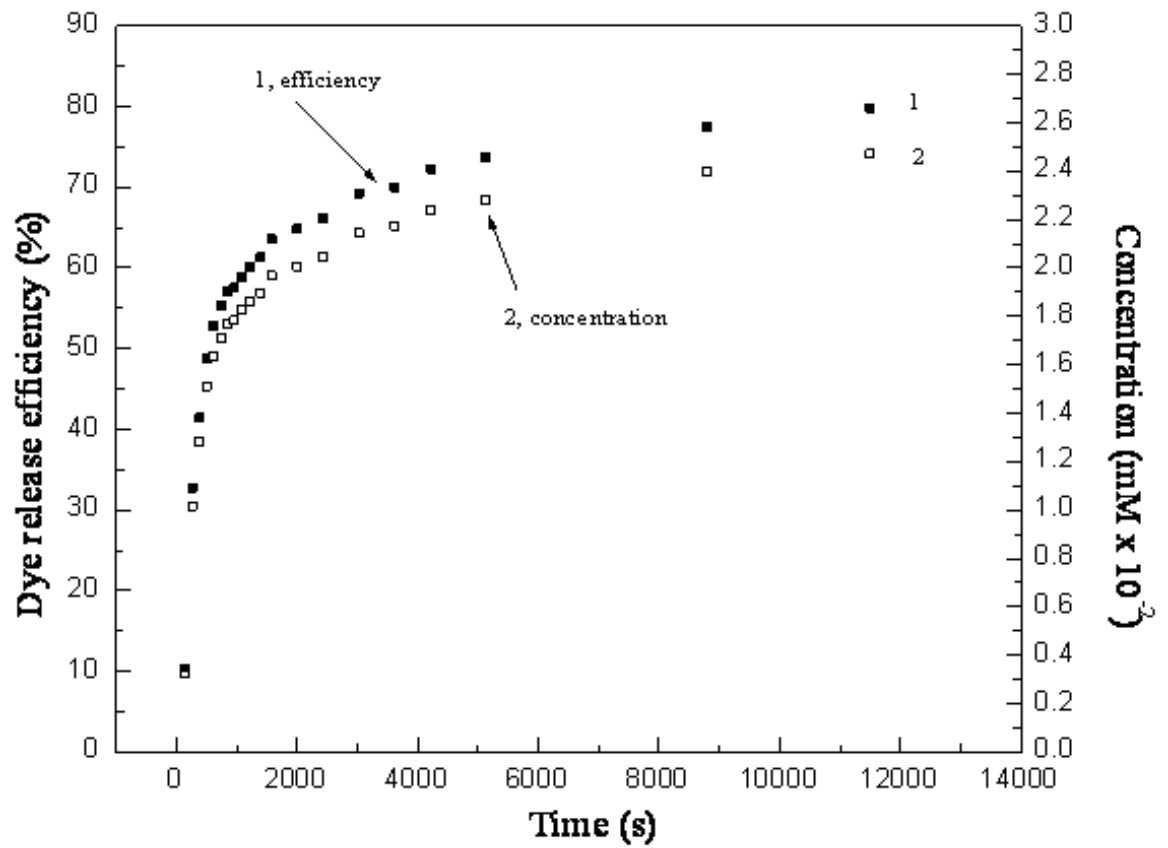

Fig.7 


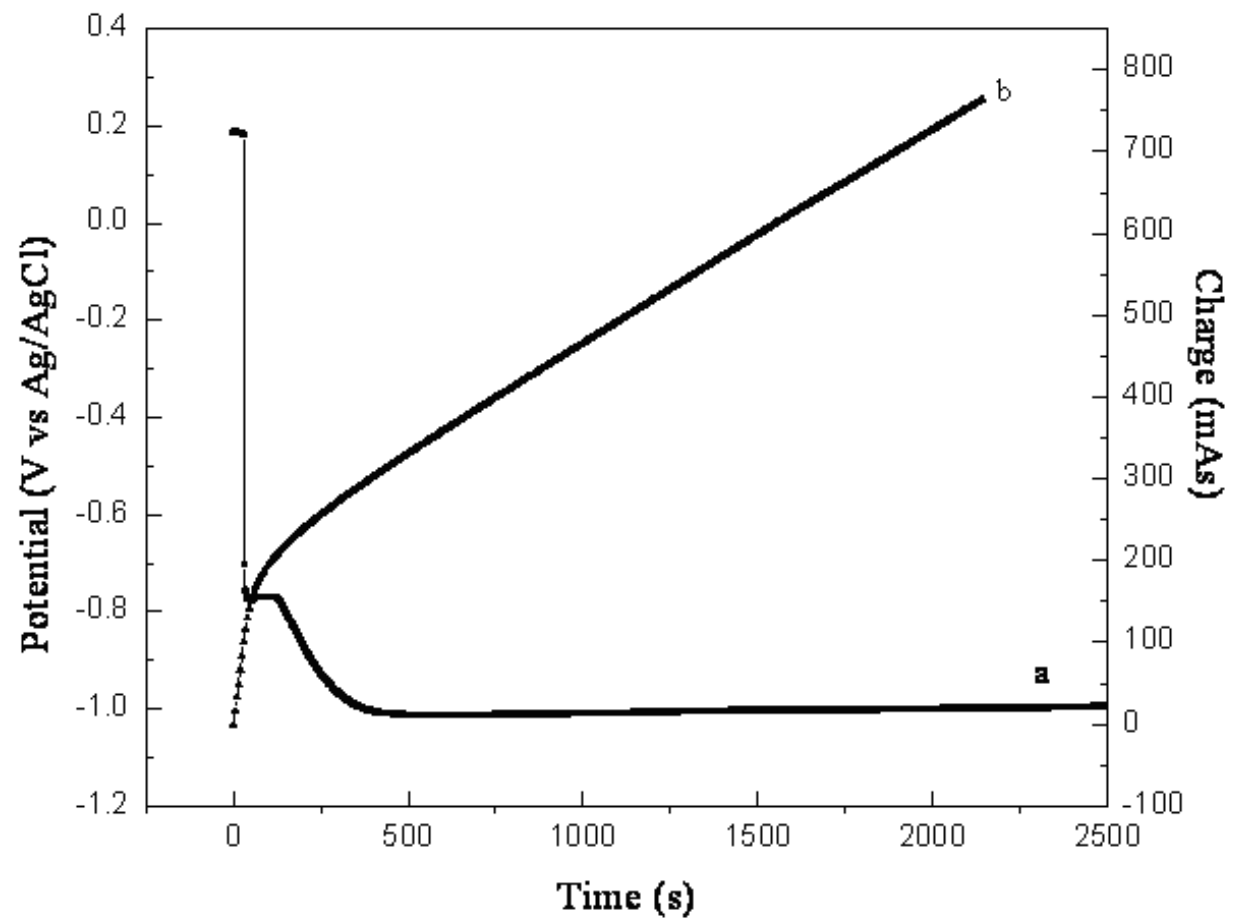

Fig.8

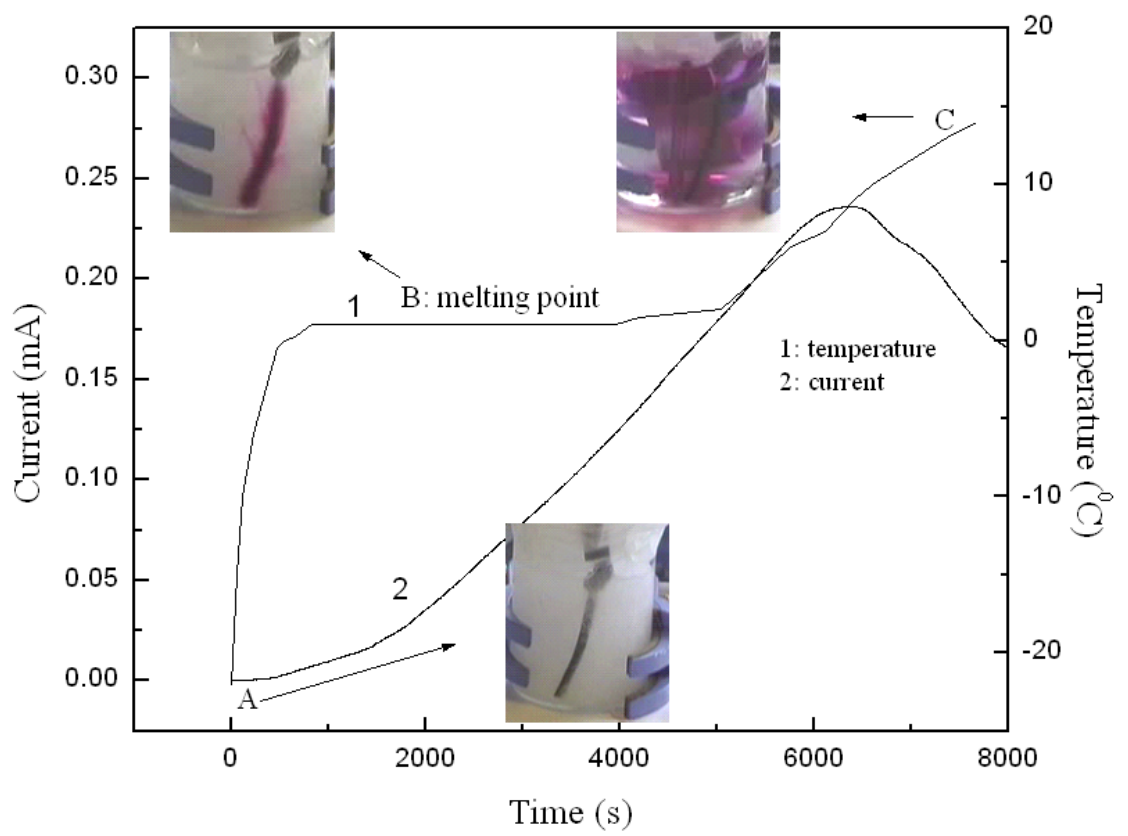

Fig. 9 